\title{
Are vector-borne pathogen co-infections complicating the clinical presentation in dogs?
}

\author{
Anna Sara De Tommasi ${ }^{1}$, Domenico Otranto ${ }^{1 *}$, Filipe Dantas-Torres ${ }^{1,2}$, Gioia Capelli ${ }^{3}$, Edward B Breitschwerdt ${ }^{4}$ \\ and Donato de Caprariis ${ }^{1}$
}

\begin{abstract}
Background: Infection by two or more canine vector-borne disease (CVBD)-causing pathogens is common in subtropical and tropical regions where vectors are plentiful. Co-infections may potentiate disease pathogenesis, thereby altering clinical manifestations typically associated with singular infections. These factors complicate diagnosis, treatment and can adversely influence prognosis if the practitioner fails to suspect, document, and treat each concurrent infection. The spectrum of pathogens co-infecting dogs may change over time in a given practice location due to the rapid expansion of arthropods and their associated vectored agents, and international transit among pets and wild animals. This applies, for example, to Dirofilaria immitis and Leishmania infantum, the distributions of which have expanded from northern to southern Italy, and vice versa, respectively. Indeed, mixed infections by D. immitis and L. infantum have only been reported once in Italy, probably due to the fact that competent vectors for these infections do not usually occur in the same geographical areas. Thus, information that would help practitioners to identify clinical presentations in dogs co-infected by D. immitis and L. infantum and other CVBD-causing pathogens is scant.
\end{abstract}

Findings: This manuscript describes the clinical history and physical examination of findings for 7 CVBD co-infected dogs that were examined because of a spectrum of clinical signs. Five dogs were co-infected with $L$. infantum and Ehrlichia canis, one dog with L. infantum, E. canis and D. immitis and the remaining dog with L. infantum and D. immitis.

Conclusions: The clinical signs and haematological abnormalities associated with the diagnostic evaluation and treatment of these dogs is discussed. Also, the usefulness of bone marrow specimens for the molecular diagnosis of CVBDs and for the enhanced monitoring of treatment response is emphasized.

Keywords: Co-infection, Dirofilaria immitis, Ehrlichia canis, Leishmania infantum, Bone marrow

\section{Findings}

Canine vector-borne diseases (CVBDs) are caused by a spectrum of pathogens that are transmitted by arthropods, including ticks, fleas, mosquitoes and phlebotomine sand flies [1]. Dogs are reservoir hosts for several arthropod-borne pathogens, some of which are of major zoonotic concern [2]. In Italy, dogs may be infected by several CVBD-causing pathogens, such as Leishmania infantum, Ehrlichia canis, Babesia spp., Bartonella spp., Cercopithifilaria spp., Hepatozoon canis, Anaplasma platys,

\footnotetext{
* Correspondence: domenico.otranto@uniba.it

'Department of Veterinary Public Health, Faculty of Veterinary Medicine, University of Bari, Str. prov. per Casamassima km 3, Valenzano, Bari 70010, Italy

Full list of author information is available at the end of the article
}

Dirofilaria immitis and Dirofilaria repens [3]. Canine leishmaniosis (CanL) and canine monocytic ehrlichiosis (CME) are both severe systemic diseases and each can be characterized by a wide range of overlapping clinical signs (e.g., lymph node enlargement, weight loss, and splenomegaly). Dogs with CanL may also present skin alterations (alopecia, furfuraceous dermatitis, ulcers, and nodular lesions) [4], whereas dogs infected with $E$. canis may display haemorrhagic disorders [5]. Heartworm disease, caused by $D$. immitis, may be an asymptomatic infection or may be associated with pulmonary and cardiovascular illnesses (e.g. cough, dyspnoea, exercise intolerance, ascites, renal failure, and lethargy), with severity of disease mostly related to the nematode burden [6]. Molecular assays, serological testing and cytology

\section{Biomed Central}


performed on different biological tissues (bone marrow and lymph node for CanL and blood for CME, blood for dirofilariosis) are the most frequently used tests for diagnosing the respective infections $[7,8]$. Recommended treatment for CanL is a combination of meglumine antimoniate or miltefosine with allopurinol [9], doxycycline for CME [10], and melarsomine dihydrochloride as adulticide treatment for dirofilariosis, followed by macrocyclic lactones as larvicide [11].

In subtropical and tropical regions where vectors are plentiful, co-infections may potentiate disease pathogenesis, thereby altering clinical disease manifestations typically associated with singular infections. These factors complicate diagnosis, treatment and can adversely influence prognosis if the practitioner fails to suspect, document and treat each concurrent infection [12-16]. To the authors' knowledge, co-infection with $D$. immitis and $L$. infantum has only been reported in a single dog from Italy [17], probably due to the fact that the geographical distribution of the vectors for these infections does not usually overlap. Under the above circumstances, information regarding the clinical presentation of dogs co-infected by $D$. immitis and $L$. infantum is scant, thus representing a challenge for practitioners in their attempt to diagnose such conditions.

This manuscript describes the clinical history of seven dogs that were examined due to highly variable disease presentations. Co-infection with two or more CVBDs was diagnosed in all seven dogs.

From January to December 2011, 7 dogs were referred to the teaching hospital of The Department of Veterinary Medicine (University of Bari, Italy) for diagnostic evaluation (Table 1). Dogs were of different breeds, both sexes, and various ages and came from an area of southern Italy that is endemic for $L$. infantum and E. canis [3]. At admission, one dog (no. 5) had a severe tick infestation, whereas the other dogs were not infested at the time of examination, but had no history of acaricide treatment. When referred, clinical signs included depression $(2 / 7)$, weight loss (2/7), hyperthermia (1/7), anorexia (3/7), exercise intolerance (1/7), pale mucous membranes (2/7), lymph node enlargement (5/7), tongue ulcers (1/7), furfuraceous dermatitis (1/7), ulcerative granulomatous dermatitis of prepuce (1/7), cough (1/7), lameness (1/7), epistaxis (1/7) and multiple mammary nodules (1/7). Complete blood counts (CBC) were obtained using an automated cell counter (Abbott Cell-Dyn 3700). Serum proteins were determined by agarose gel electrophoresis. The following haematological and serum biochemistry parameters were recorded: haemoglobin concentration $(\mathrm{Hb})$, haematocrit (Hct), nucleated red blood cells (nRBC), white blood cells (WBC), platelet count (PLT), total serum protein (TP), albumin and $\gamma$-globulin. Haematological reference ranges were previously determined [18]. Blood, buffy coat, lymph node, and bone marrow smears were prepared and stained using the MGG Quick Stain (Bio Optica Spa, Italy) and stained-smears were examined by light microscopy for the presence of intracellular inclusions (or free forms) of common tick-borne pathogens and L. infantum [19]. All dogs had a polyclonal gammopathy. Anaemia and thrombocytopenia were found in five and four dogs, respectively. Cytological examination of lymph node and bone marrow smears resulted in the identification of $L$. infantum amastigotes in 6/7 dogs (nos. 1, 3, 4, 5, 6, and 7). In dogs 1 and 2, nematode microfilariae, identified as $D$. immitis, were initially confirmed by direct examination of blood smears and modified Knott's test [20]. Dirofilaria immitis infection in these two dogs was further confirmed by the detection of circulating antigens using a commercial assay (SNAP heartworm antigen test; IDEXX Laboratories, Milano, Italy) and by PCR specific amplification of Dirofilaria spp. DNA, that was performed as described elsewhere [21]. PCR on blood and bone marrow samples was also performed for detection of L. infantum, Ehrlichia, Anaplasma and Babesia species, as previously described [19]. Five dogs were co-infected with $L$. infantum and $E$. canis, one dog with L. infantum, E. canis and D. immitis and the remaining dog with E. canis and D. immitis. The finding of microfilariae of $D$. immits in the bone marrow cytology was most likely due to the presence of blood in the bone marrow sample even if microfilariae have rarely been found in the bone marrow of dogs [22].

Dogs co-infected by L. infantum and E. canis were treated with a combination of meglumine antimoniate (50 mg/kg/bid/SC) and allopurinol (10 mg/kg/bid/OS) [23] and with doxycycline $(10 \mathrm{mg} / \mathrm{kg} / \mathrm{die} / \mathrm{OS})$. Dogs 1 and 2 were also treated with melarsomine $2.5 \mathrm{mg} / \mathrm{kg} / \mathrm{IM}$ for two days for heartworm infections [6].

After therapy with doxycycline, whole blood PCR was negative for $E$. canis, whereas $E$. canis DNA was amplified from the bone marrow in five dogs (nos. 1, 2, 3, 4, and 6), which had normal platelet counts but failed to reduce gammopathy. For these dogs, an additional four weeks of treatment with doxycycline $(10 \mathrm{mg} / \mathrm{kg} / \mathrm{die}$ OS) was given. After two weeks PCR assays were negative on both blood and bone marrow samples from all five dogs and remained negative when retested at 4 weeks post-treatment.

\section{Discussion}

Clinical evaluation of the seven co-infected dogs described in this case series illustrates the diagnostic, therapeutic and management challenges imposed by the spectrum of CVBDs prevalent in southern Italy. These concurrent infections can induce clinical illness, as illustrated by dog 1 , that was infected by E. canis, L. infantum and D. immitis, as compared to asymptomatic infection in $\operatorname{dog} 2$, that was infected with $E$. canis and D. immitis. Co-infections with $E$. canis and $L$. infantum are frequently 
Table 1 Breed, sex, age (in years), description of clinical signs, laboratory abnormalities and diagnostic test results for 7 dogs co-infected by two or more canine vector-borne diseases causing pathogens

\begin{tabular}{|c|c|c|c|c|c|c|c|c|c|c|}
\hline \multirow[t]{2}{*}{ Dog no./breed } & \multirow[t]{2}{*}{ Sex } & \multirow[t]{2}{*}{ Age } & \multirow[t]{2}{*}{ Clinical signs } & \multirow[t]{2}{*}{ Laboratory abnormalities } & \multicolumn{4}{|c|}{ Cytology } & \multicolumn{2}{|r|}{ PCR } \\
\hline & & & & & Blood & Buffy coat & Lymph node & Bone marrow & Blood & Bone marrow \\
\hline 1/Fila Brasileiro & $\mathrm{F}$ & 5.5 & $\begin{array}{l}\text { Weight loss, anorexia, exercise } \\
\text { intolerance, pale mucous } \\
\text { membranes, lymph node } \\
\text { enlargement, furfuraceous } \\
\text { dermatitis }\end{array}$ & $\begin{array}{l}\text { Anaemia, polyclonal gammopathy, } \\
\text { low PLT }\end{array}$ & Diro & - & Leish & Leish, Diro & Ehrl, Diro & Ehrl, Leish \\
\hline 2/Fila Brasileiro & M & 6 & Asymptomatic & Polyclonal gammopathy & Diro & - & - & Diro & Ehrl, Diro & Ehrl \\
\hline 3/Mongrel & $\mathrm{F}$ & 5 & $\begin{array}{l}\text { Tongue ulcers, lymph node } \\
\text { enlargement }\end{array}$ & Polyclonal gammopathy & - & - & Leish & Leish & Ehrl & Ehrl, Leish \\
\hline 4/English setter & M & 9 & $\begin{array}{l}\text { Ulcerative granulomatous } \\
\text { dermatitis of prepuce }\end{array}$ & $\begin{array}{l}\text { Anaemia, polyclonal gammopathy, } \\
\text { low PLT }\end{array}$ & nd & nd & Leish & Leish & Ehrl & Ehrl, Leish \\
\hline 5/Siberian Husky & M & 8 & $\begin{array}{l}\text { Coughing, anorexia, depression, } \\
\text { hyperthermia, pale mucous } \\
\text { membranes, lymph node } \\
\text { enlargement }\end{array}$ & $\begin{array}{l}\text { Anaemia, polyclonal gammopathy, } \\
\text { low PLT }\end{array}$ & - & - & Leish & Leish & Ehrl & Ehrl, Leish \\
\hline 6/Doberman & $\mathrm{F}$ & 4 & $\begin{array}{l}\text { Depression, weight loss, lymph } \\
\text { node enlargement, multiple } \\
\text { mammary nodules }\end{array}$ & $\begin{array}{l}\text { Anaemia, hyperproteinemia, polyclonal } \\
\text { gammopathy, low PLT }\end{array}$ & - & - & Leish & Leish & Ehrl & Ehrl, Leish \\
\hline 7/Schnauzer & $\mathrm{F}$ & 5.5 & $\begin{array}{l}\text { Lameness, anorexia, lymph node } \\
\text { enlargement, epistaxis }\end{array}$ & Anaemia, polyclonal gammopathy & - & - & Leish & Leish & Ehrl & Leish \\
\hline
\end{tabular}

Abbreviations: $F$ female; $M$ male; PLT platelets; $n d$ not done; Diro Dirofilaria immitis; Leish Leishmania infantum; Ehrl Ehrlichia canis. 
detected in the Mediterranean region [24] whereas to date, co-infection with $D$. immitis and $L$. infantum has only been reported in a dog from Italy [17]. The region from which both dogs originated is endemic for $L$. infantum and E. canis [3]. Documentation of two additional cases of heartworm disease indicates that $D$. immitis occurs in autochthonous foci in southern Italy (i.e., both dogs had lived in this area since they were puppies, and had no travel history), thus confirming the spread of this helminthic infestation in this region $[25,26]$. Undoubtedly, infection with two or more pathogens complicates the clinical presentation, which provides the basis for the veterinarian's diagnostic and therapeutic recommendations. In addition, co-infection with multiple CVBDs impacts the severity of haematological abnormalities in dogs, and poses challenges in terms of therapeutic strategies to be applied to each individual patient [18]. For example, L. infantum may impair the cellular and humoral immune response of the host, which may favour the establishment or the reactivation of a pre-existing $E$. canis infection [27]. Moreover, E. canis causes a reduction in major histocompatibility complex of class II receptors, which could ultimately enhance the clinical progression of CanL [28].

Out of five dogs infected with L. infantum, only dog 1 had clinical signs suggestive of CanL (e.g., lymphadenopathy, dermatitis and onychogryphosis), whereas the laboratory abnormalities (normocytic, normochromic nonregenerative anaemia, thrombocytopenia, and gammopathy) in the remaining $L$. infantum-infected dogs overlapped with laboratory abnormalities associated with CME [19]. This suggests that when infection with multiple pathogens is involved, the clinical presentation might be unpredictable and specific clinical or haematological abnormalities cannot be definitively ascribed to a single pathogen. For example, the polyclonal gammopathy detected in all seven dogs in this case series might be the consequence of a chronic antigenic stimulation [29] caused either by L. infantum, E. canis or D. immitis or any combination of these three pathogens.

Diagnosis of single or multiple CVBDs should rely on epidemiological information, including travel history, on the clinical status of the dog and on a panel of laboratory diagnostic tests [19]. In the cases reported herein, a definitive diagnosis of co-infection required a combination of clinical suspicion in conjunction with documentation of abnormal laboratory findings, and diagnostic confirmation by microscopy, serology and PCR, preferably using both blood and bone marrow specimens when attempting to confirm the diagnosis of E. canis and L. infantum infections. Accordingly, the tissues most frequently used for the diagnosis of E. canis infections are blood and bone marrow [7,30]. Monitoring the response following doxycycline administration in dogs suffering from ehrlichiosis is pivotal in distinguishing persistently infected sick dogs unsuccessfully treated, from dogs that achieve clinical and haematological recovery, but remain infected as compared to those dogs that recover and clear the pathogen [10]. Although preliminary and limited in quantity, data herein reported indicates that under natural exposure conditions, PCR on bone marrow aspirates may be a reliable method for the evaluation of the treatment response in dogs with CME. In our experience, when infections with E. canis and L. infantum occur in dogs with severe clinical or haematological abnormalities, these infections should be treated simultaneously to improve the dogs clinical status, before treating for D. immitis.

\section{Conclusions}

The atypical clinical signs and mild to severe haematological abnormalities described in these seven co-infected dogs highlight the importance of a holistic diagnostic approach that includes microscopy, serology and PCR testing, when dealing with CVBDs in endemic areas. This report also supports the potential utility of using bone marrow specimens as a biological tissue for the molecular diagnosis of CVBDs and for monitoring of the treatment response in dogs with $\mathrm{CME}$. Our results further stress the need for continued development of multi-pathogen detection methods for CVDBs in endemic and non-endemic regions.

\section{Competing interest}

The authors declare that they have no competing interests.

\section{Authors' contributions}

ASDT and DdC conceived the study and documented clinical cases. ASDT, DdC, DO, FDT, EBB and GC drafted and revised of manuscript. All authors read and approved the final version of manuscript.

\section{Author details}

${ }^{1}$ Department of Veterinary Public Health, Faculty of Veterinary Medicine, University of Bari, Str. prov. per Casamassima km 3, Valenzano, Bari 70010, Italy. ${ }^{2}$ Departamento de Imunologia, Centro de Pesquisas Aggeu Magalhães, Fundação Oswaldo Cruz - Pernambuco, Av. Prof. Moraes Rego s/n, Recife, PE 50670-420, Brazil. ${ }^{3}$ Istituto Zooprofilattico Sperimentale delle Venezie, Viale dell'Università, Legnaro, Padova 10, 35020, Italy. ${ }^{4}$ Intracellular Pathogens Research Laboratory, Center for Comparative Medicine and Translational Research, College of Veterinary Medicine, North Carolina State University, Raleigh, North Carolina, USA.

Received: 17 January 2013 Accepted: 14 February 2013 Published: 15 April 2013

\section{References}

1. Otranto D, Dantas-Torres F, Breitschwerdt EB: Managing canine vectorborne diseases of zoonotic concern: part one. Trends Parasit 2009, 25:157-163.

2. Beugnet F, Marié J: Emerging arthropod-borne diseases of companion animals in Europe. Vet Parasitol 2009, 163:298-305.

3. Otranto D, Dantas-Torres F: Canine and feline vector-borne diseases in Italy: current situation and perspectives. Parasit Vectors 2010, 3:2.

4. Ciaramella P, Oliva G, Luna RD, Gradoni L, Ambrosio R, Cortese L, Scalone A, Persechino A: A retrospective clinical study of canine leishmaniasis in 150 dogs naturally infected by Leishmania infantum. Vet Rec 1997, 141:539-543. 
5. Harrus S, Aroch I, Lavy E, Bark H: Clinical manifestations of infectious canine cyclic thrombocytopenia. Vet Rec 1997, 141:2247-2250.

6. Nelson CT, MCCall JW, Rubin SB, Buzhardt LF, Dorion DW, Graham W, Longhofer SL, Guerrero J, Robertson-Plouch C, Paul A: Guidelines for the diagnosis, prevention and management of heartworm (Dirofilaria immitis) infection in dogs. Vet Parasitol 2005, 133:255-266.

7. Harrus S, Kenny M, Miara L, Aizenberg I, Waner T, Shaw S: Comparison of simultaneous splenic sample PCR with blood sample PCR for diagnosis and treatment of experimental Ehrlichia canis infection. Antimicrob Agents Chemother 2004, 48:4488-4490.

8. Baneth G, Aroch I: Canine leishmaniasis: A diagnostic and clinical challenge. Vet J 2008, 175:14-15.

9. Dantas-Torres F, Solano-Gallego L, Baneth G, Ribeiro VM, de Paiva-Cavalcanti M, Otranto D: Canine leishmaniosis in the Old and New worlds: unveiled similarities and differences. Trends Parasitol 2012, 28:531-538.

10. Neer TM, Breitschwerdt EB, Greene RT, Lappin MR: Consensus statement on ehrlichial disease of small animals from the infectious disease study group of the ACVIM. American college of veterinary internal medicine. J Vet Intern Med 2002, 16:309-315.

11. Colby KN, Levy JK, Dunn KF, Michaud Rl: Diagnostic, treatment, and prevention protocols for canine heartworm infection in animal sheltering agencies. Vet Parasitol 2011, 176:333-341.

12. Klag $A R$, Dunbar LE, Girard CA: Concurrent ehrlichiosis and babesiosis in a dog. Can Vet J 1991, 32:305-307.

13. Tuttle AD, Birkenheuer AJ, Juopperi T, Levy MG, Breitschwerdt EB: Concurrent bartonellosis and babesiosis in a dog with persistent thrombocytopenia. JAVMA 2003, 223:1306-1310.

14. Mylonakis ME, Koutinas AF, Baneth G, Polizopoulou Z, Fytianou A: Mixed Ehrlichia canis, Hepatozoon canis, and presumptive Anaplasma phagocytophilum infection in a dog. Vet Clin Pathol 2004, 33:249-251.

15. Mekuzas Y, Gradoni L, Oliva G, Foglia Manzillo V, Baneth G: Ehrlichia canis and Leishmania infantum co-infection: a 3-year longitudinal study in naturally exposed dogs. Clin Microbiol Infect 2008, 15(Suppl 2):30-31.

16. Cortese L, Terrazzano G, Piantedosi D, Sica M, Prisco M, Ruggiero G, Ciaramella P: Prevalence of anti-platelet antibodies in dogs naturally co-infected by Leishmania infantum and Ehrlichia canis. Vet J 2011, 188:118-121.

17. Aresu L, Valenza F, Ferroglio E, Pregel P, Uslenghi F, Tarducci A, Zanatta R: Membranoproliferative glomerulonephritis type III in a simultaneous infection of Leishmania infantum and Dirofilaria immitis in a dog. J Vet Diagn Invest 2007, 19:569-572.

18. de Caprariis D, Dantas-Torres F, Capelli G, Mencke N, Stanneck D, Breitschwerdt EB, Otranto D: Evolution of clinical, haematological and biochemical findings in young dogs naturally infected by vector-borne pathogens. Vet Microbiol 2011, 149:206-212.

19. Otranto D, Testini G, Dantas-Torres F, Latrofa MS, Diniz PP, de Caprariis $D$, Lia RP, Mencke N, Stanneck D, Capelli G, Breitschwerdt EB: Diagnosis of canine vector-borne diseases in young dogs: a longitudinal study. J Clin Microbiol 2010, 48:3316-3324.

20. Otranto D, Brianti E, Dantas-Torres F, Weigl S, Latrofa MS, Gaglio G, Cauquil L, Giannetto S, Bain O: Morphological and molecular data on a Cercopithifilaria species from the dog skin. Vet Parasitol 2011, 182:221-229.

21. Latrofa MS, Montarsi F, Ciocchetta S, Annoscia G, Dantas-Torres F, Ravagnan S, Capelli G, Otranto D: Molecular xenomonitoring of Dirofilaria immitis and Dirofilaria repens in mosquitoes from north-eastern Italy by real-time PCR coupled with melting curve analysis. Parasit Vectors 2012, 5:76.

22. Bossie A: Microfilaria of Dirofilaria immitis in the bone marrow of a dog. Arch Roum Pathol Exp Microbiol 1968, 27:651-654.

23. Canine Leishmaniasis Working Group, Italian Society of Veterinarians of Companion Animals, Paltrinieri S, Solano-Gallego L, Fondati A, Lubas G, Gradoni L, Castagnaro M, Crotti A, Maroli M, Oliva G, Roura X, Zatelli A, Zini E: Guidelines for diagnosis and clinical classification of leishmaniasis in dogs. JAVMA 2010, 236:1184-1191.

24. Trotz-Williams LA, Trees AJ: Systematic review of the distribution of the major vector-borne parasitic infections in dogs and cats in Europe. Vet Rec 2003, 152:97-105.

25. Otranto D, Dantas-Torres F, Breitschwerdt EB: Managing canine vectorborne diseases of zoonotic concern: part two. Trends Parasitol 2009, 25:228-235

26. Genchi C, Di Sacco B, Cancrini G: Epizootiology of canine and feline heartworm infection in Northern Italy: possible mosquito vectors. In
Proceedings of the American Heartworm Symposium 1992. Edited by Soll MD. Batavia, IL: American Heartworm Society; 1992:39-46.

27. Barbiéri CL: Immunology of canine leishmaniasis. Parasite Immunol 2006, 28:329-337.

28. Harrus S, Waner T, Friedmann-Morvinski D, Fishman Z, Bark H, Harmelin A: Down-regulation of MHC class II receptors of DH82 cells, following infection with Ehrlichia canis. Vet Immunol Immunopathol 2003, 96:239-243

29. Harrus S, Waner T, Avidar Y, Bogin E, Peh H, Bark H: Serum protein alterations in canine ehrlichiosis. Vet Parasitol 1996, 66:241.

30. Harrus S, Waner T: Diagnosis of canine monocytotropic ehrlichiosis (Ehrlichia canis): An overview. Vet J 2011, 187:292-296.

doi:10.1186/1756-3305-6-97

Cite this article as: De Tommasi et al:: Are vector-borne pathogen coinfections complicating the clinical presentation in dogs?. Parasites \& Vectors 2013 6:97.

\section{Submit your next manuscript to BioMed Central and take full advantage of:}

- Convenient online submission

- Thorough peer review

- No space constraints or color figure charges

- Immediate publication on acceptance

- Inclusion in PubMed, CAS, Scopus and Google Scholar

- Research which is freely available for redistribution

Submit your manuscript at www.biomedcentral.com/submit
C Biomed Central 